only 2 had a significantly decreased rate of annual growth, compared to normal growth patterns of children of the same age group. In 6 children under 8 years of age the growth rate was significantly increased. (Millichap JG. Growth of hyperactive children treated with methylphenidate: a possible growth stimulant effect. In: Learning Disabilities and Related Disorders. Chicago, Year Book Med Publ, 1977) (Millichap JG, Millichap MG. Growth of hyperactive children. N Engl I Med 1975;292:1300).

Predictors of weight loss in children with ADHD treated with stimulant medication were studied retrospectively at the Schneider Children's Hospital, New Hyde Park, New York. (Schertz M et al. Pediatrics Oct 1996;98:763-769). Using body mass index as a measure, pretreatment weight was a significant predictor of stimulant-related weight loss, heavier children losing more weight than thinner children. In overweight ADHD children, stimulant medication may provide a secondary benefit, improving self-esteem.

\title{
METHYLPHENIDATE DOSING SCHEDULES
}

Efficacy and side effects of twice daily (bid) and three times daily (tid) methylphenidate (MPH) dosing schedules (mean dose, $8 \mathrm{mg}, 0.3 \mathrm{mg} / \mathrm{kg}$ ) in 25 boys with attention deficit hyperactivity disorder (ADHD) were compared in a 5-week, placebo-controlled, crossover evaluation at the Departments of Psychiatry and Pediatrics, University of Chicago. Three times daily dosing provided greater improvement than the bid schedule on Hyperactivity/Impulsivity Conners Parent and Teacher Rating scales. Compared to placebo, appetite and total sleep time were adversely affected by tid dosing but not bid schedules. The incidence of side effects with tid compared to bid dosing was not significantly different. No effect on weight was noted in this short time period. (Stein MA, Blondis TA, Schnitzler ER, Roizen NJ et al. Methylphenidate dosing: twice daily versus three times daily. Pediatrics Oct 1996;98:748-756). (Reprints: Dr Mark A Stein, Section of Child and Adolescent Psychiatry, 5841 S Maryland Ave, Chicago, IL 60637).

COMMENT. This short term study shows that more frequent, smaller dose, three times daily MPH treatment is often preferable to twice daily dosing schedules. The incidence of insomnia, usually regarded as a disadvantage of afternoon doses, is not increased, and teacher and parent ratings of MPH efficacy are benefited. Doses of MPH for ADHD should be selected for each individual child according to the time of occurrence of symptoms and not with regard to the pattern of possible side effects. An evening free from parentchild conflict and a home-work assignment satisfactorily completed may lead to improved self esteem and better classroom performance. Closer monitoring of MPH dosing schedules, using both parent and teacher abbreviated reports, should result in optimal treatment efficacy.

The benefits of a group treatment developmental approach, involving patients and their families, as a supplement to medication, are reported from the Department of Psychiatry and Behavioral Sciences, Stanford University School of Medicine, CA. (Lock J. Developmental considerations in the treatment of school-age boys with ADHD: an example of a group treatment approach. I Am Acad Child Adolesc Psychiatry Nov 1996;35:1557-1559).

CARDIOVASCULAR EFFECTS OF TRICYCLIC ANTIDEPRESSANTS

Twenty-four pediatric studies, published from various centers between 1967 and 1996, involving 730 children and adolescents treated with imipramine, amitryptiline, desipramine, or nortryptiline, were surveyed for 
cardiovascular side effects at the Massachusetts General Hospital, Boston, MA. Treatment with tricyclic antidepressants (TCA) caused small increases in blood pressure and heart rate, and lengthening of PR, QRS, and QT conduction parameters on the ECG. Imipramine may be associated with lower rates of sinus tachycardia and intraventricular conduction lengthening than other TCAs, and desipramine may have the greatest tendency to cause QT prolongation. ECG abnormalities were related to the dose and relatively higher serum TCA levels. ECG monitoring is recommended with doses of TCAs of $2.5 \mathrm{mg} / \mathrm{kg}$ day $(1 \mathrm{mg} / \mathrm{kg}$ day for nortryptyline), and doses more than $5 \mathrm{mg} / \mathrm{kg}$ day should be avoided. Lightheadedness or headaches signal the need for a check of vital signs, ECG, and TCA serum levels. Guidelines for monitoring ECG and vital signs in children receiving TCAs are suggested. (Wilens TE, Biederman J, Baldessarini $\mathrm{RJ}$ et al. Cardiovascular effects of therapeutic doses of tricyclic antidepressants in children and adolescents. I Am Acad Child Adolesc Psychiatry Nov 1996;35:1491-1501). (Reprints: Dr Wilens, ACC 725, Massachusetts General Hospital, Boston, MA 02114).

COMMENT. Tricyclic antidepressants are a second-line choice of medication for ADHD, sometimes favored in children with psychiatric comorbidity or enuresis. Although in general the cardiovascular effects are minor, tachycardia and shortness of breath, and occasional reports of idiosyncratic fatalities in TCA-treated children are a concern to some practitioners. Without frequent ECG monitoring, it is likely that these cardiovascular abnormalities and associated symptoms are often unrecognized. Children engaged in sporting activities especially should be closely examined for cardiac related side effects, and alternative treatments substituted.

Protriptyline for ADHD. Side effects were particularly prominent in a trial of protriptyline in 13 children with ADHD, and less than $50 \%$ showed a positive response. (Wilens TE, Biederman J, Abrantes AM, Spencer TJ. A naturalistic assessment of protriptyline for attention-deficit hyperactivity disorder. I Am Acad Child Adolesc Psychiatry Nov 1996;35:1485-1490).

\section{SEASON OF BIRTH: A RISK FACTOR FOR ADHD}

Seasonal variations in the birth patterns of 140 ADHD boys compared to 120 controls were studied at the Massachusetts General Hospital, Boston, with particular reference to issues of psychiatric and cognitive comorbidity and familiality. Statistically significant peaks for September births were noted in ADHD children with comorbid learning disabilities and in those without psychiatric comorbidity. A trend toward an increase in winter births was also evident. A first-trimester viral hypothesis for ADHD is suggested. (Mick E, Biederman J, Faraone SV. Is season of birth a risk factor for attention-deficit hyperactivity disorder? IAm Acad Child Adolesc Psychiatry Nov 1996;35:14701476). (Reprints: Dr Biederman, Pediatric Psychopharmacology Unit (ACC 725), Massachusetts General Hospital, Fruit Street, Boston, MA 02114).

COMMENT. Exposure to viral infections during winter months in the first trimester of fetal life or at the time of birth may be a predisposing factor in $10 \%$ of ADHD subjects having comorbid learning disabilities. Prenatal or perinatal infection as a possible cause of ADHD requires further evaluation.

Familial transmission of ADHD is supported by a prospective fouryear follow-up study of siblings of ADHD children, one fourth having developed ADHD and one half showing evidence of school failure. (Faraone SV, Biederman J et al. I Am Acad Child Adolesc Psychiatry Nov 1996;35:1449-1459). 